\title{
Preparation and assessment of poly(methacrylic acid-co- ethylene glycol dimethacrylate) as a novel disintegrant
}

\author{
Siraprapa Chansatidkosol, Praneet Opanasopit, Tanasait Ngawhirunpat, \\ Sontaya Limmatvapirat, Prasert Akkaramongkolporn* \\ Department of Pharmaceutical Technology, Faculty of Pharmacy, Silpakorn University, Nakhon Pathom, Thailand \\ *For correspondence: Email: akkaramongkol_p@su.ac.th
}

\begin{abstract}
Purpose: To prepare and evaluate poly(methacrylic acid (MAA)-co-ethylene glycol dimethacrylate (EGD)) as a tablet disintegrant.

Methods: Poly(MAA-co-EGD) in acid (H) and sodium (Na) forms at cross-linker (EGD) levels of 0.25 $16 \%$ were synthesized and subjected to Fourier transform infrared spectroscopy. Swelling capacity, disintegration efficiency and cytotoxicity to Caco-2 cells were determined using standard procedures.

Results: Poly(MAA-co-EGD) in acid $(\mathrm{H})$ and sodium $(\mathrm{Na})$ forms were successfully prepared. In contact with water, the polymers in $\mathrm{Na}$ form swelled more than those in $\mathrm{H}$ form. The swelling capacities of polymers in $\mathrm{H}$ and $\mathrm{Na}$ forms decreased with increasing amounts of cross-linker. Incorporation of the polymers accelerated the disintegration of microcrystalline cellulose tablets (placebo), and the disintegration efficiency depended on the salt form and amount of cross-linker. The Na salt form of the polymer crosslinked at $16 \%$ EGD was the best candidate disintegrant. When used at 2.5 and $10 \%$, the selected polymer effectively promoted the disintegration and drug release of propranolol hydrochloride tablets. Moreover, cytotoxicity tests showed that it was non-toxic to Caco-2 cells.

Conclusion: The developed poly(MAA-co-EGD) possesses good disintegration and dissolution functionalities. Thus, it may be adopted as a new super-disintegrant for fast-release tablets.
\end{abstract}

Keywords: Tablet disintegrant, Methacrylic acid, Ethylene glycol dimethacrylate, Propranolol hydrochloride

\footnotetext{
This is an Open Access article that uses a funding model which does not charge readers or their institutions for access and distributed under the terms of the Creative Commons Attribution License (http://creativecommons.org/licenses/by/4.0) and the Budapest Open Access Initiative (http://www.budapestopenaccessinitiative.org/read), which permit unrestricted use, distribution, and reproduction in any medium, provided the original work is properly credited.

Tropical Journal of Pharmaceutical Research is indexed by Science Citation Index (SciSearch), Scopus, International Pharmaceutical Abstract, Chemical Abstracts, Embase, Index Copernicus, EBSCO, African Index Medicus, JournalSeek, Journal Citation Reports/Science Edition, Directory of Open Access Journals (DOAJ), African Journal Online, Bioline International, Open-J-Gate and Pharmacy Abstracts
}

\section{INTRODUCTION}

The rapid disintegration of tablets and dissolution of drugs are generally assisted by disintegrants, which are categorized into traditional disintegrants and super-disintegrants. Generally, the traditional disintegrants are hydrophilic, linear or branch polymeric substances such as starch, gum and un-crosslinked cellulose, while the super-disintegrants, some of which are modified from the traditional disintegrants, are hydrophilic crosslinked polymeric substances such as croscarmellose sodium, sodium starch glycolate, crospovidone, and polacrilin potassium. The super-disintegrants have superior disintegrating efficiency, and accordingly require lower amounts $(2-10 \%)$ for tablet disintegration than the traditional disintegrants. Owing to their 
hydrophilic nature, most disintegrants function through wicking and swelling. Other mechanisms that are occasionally involved in disintegrating action of disintegrants include deformation recovery and electric particle repulsion [1]. Despite the number of disintegrants present in the market, several efforts have been made to develop new and more efficient disintegrants. For instance, previous works showed that acidhydrolyzed yam and breadfruit starches enhanced the disintegration of paracetamol tablets [2,3]. Alcohol-alkaline treated rice starch has been reported to be a very effective disintegrant for propranolol hydrochloride tablets [4]. Hydrochlorothiazide tablets containing the mucilage obtained from Mimosa pudica showed rapid disintegration capacity [5]. The disintegration property of crosslinked polyalkylammonium polymers was evaluated using hydrochlorothaizide and aspirin tablets as the model formulations. The results showed that the crosslinked polyalkylammonium polymer was a powerful disintegrant for both drug tablets [6]. Other developed novel disintegrants with improved efficiency were reported in recent publications $[7,8]$.

The present study was aimed at developing a new efficient disintegrant poly(MAA-co-EGD) by copolymerization of methacrylic acid (MAA) and ethylene glycol dimethycrylate (EGD). The two monomers have been used for fabricating various biocompatible polymeric materials (hydrogels) intended for biomedical and pharmaceutical applications [9-11]. Since the poly(MAA-co-EGD) has hydrophilic structure it was anticipated that it should exhibit swelling property and hence disintegrating action.

\section{EXPERIMENTAL}

\section{Materials}

Methacrylic acid, ethylene glycol dimethacrylate, benzoyl peroxide were products of SigmaAldrich, Germany; propranolol hydrochloride was purchased from Beijing ShuangLu Pharmaceutical Ltd., China, while microcrystalline cellulose (Avicel ${ }^{\circledR}$ PH101) was obtained from FMC Corporation, USA. Sodium starch glycolate $\left(\right.$ Explotab $^{\circledR}$ ) was purchased from JRS Pharma, Germany, while magnesium stearate was obtained from Mallinckrodt Inc., USA.

\section{Synthesis of poly(MAA-co-EGD) in $\mathrm{H}$ and $\mathrm{Na}$ form}

Differently-crosslinked poly(MAA-co-EGD) in $H$ form were synthesized by a modified method
$[9,10]$, as depicted in Figure 1. Benzoyl peroxide (1 g) and MAA (10 g) were reacted with EGD (crosslinking agent) at $0.25,2,8$ and $16 \%$ EGD mole of in an Erlenmeyer flask containing $10 \mathrm{ml}$ of deionized water was added to the mixture. The mixture was continuously agitated at $80^{\circ} \mathrm{C}$ in a silicone oil bath. Under this condition, the reacting mixture gradually transformed into a white polymeric paste. The polymer was washed with ethanol and deionized water and dehydrated in a hot air oven at $60{ }^{\circ} \mathrm{C}$ for $24 \mathrm{~h}$. Each dried polymer was ground, screened through an 80 mesh sieve, and stored in a sealed bottle.

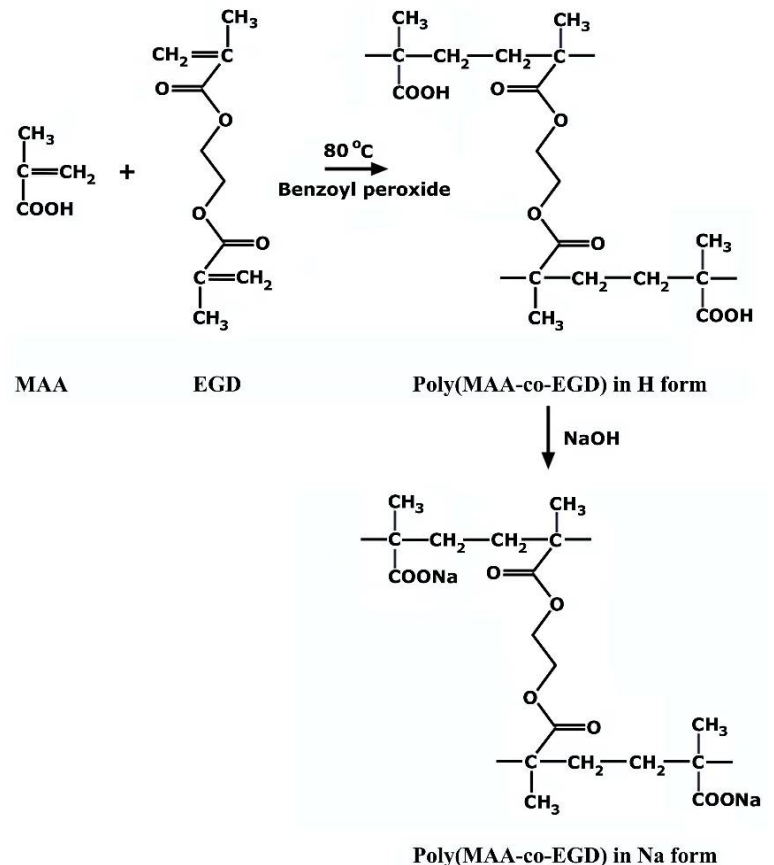

Figure 1: Synthesis and structure of poly(MAA-coEGD)

The Na salt of poly(MAA-co-EGD) was prepared by dispersing a portion of the dried polymers in $\mathrm{H}$ form in $1 \mathrm{~N} \mathrm{NaOH}$ at a volume ratio of $1: 50$ for $24 \mathrm{~h}$. Thereafter, the treated polymer was collected by filtration and washed with deionized water until the $\mathrm{pH}$ was neutral. The washed polymer was dehydrated dried in a hot air oven at $60{ }^{\circ} \mathrm{C}$ for $24 \mathrm{~h}$, screened through an 80 mesh sieve, and stored in a sealed bottle.

Fourier transform infrared (FTIR) spectroscopy

All samples were measured with $\mathrm{KBr}$ disc process using Fourier transform infrared spectrophotometer (Magna 4700, Nicolet, USA) in the wavenumber range of $400-4000 \mathrm{~cm}^{-1}$.

\section{Determination of swelling capacity}

Each polymer was carefully poured into a 
graduated cylinder and tapped to obtain a constant volume $\left(\mathrm{V}_{1}\right)$. Then, excess volume of deionized water was carefully poured into the cylinder. After soaking for $2 \mathrm{~h}$, the volume of swollen polymer $\left(\mathrm{V}_{2}\right)$ was read and the \% swelling capacity was computed as described in [12] using the relation:

Swelling capacity $(\%)=100 \times\left(V_{2}-V_{1}\right) / V_{1}$

Assessment of disintegrating efficiency in placebo microcrystalline cellulose (MCC) tablet

Each polymer (10\%) was mixed with MCC for 15 $\min$ and then an accurately weighed portion of the mixture (100 $\mathrm{mg}$ ) was compressed using a hydraulic press (P/N 15011/25011, Specac, UK) equipped with $6.5 \mathrm{~mm}$ flat-faced punches at a constant force (1 ton) of compression. The compressed tablets were then examined for disintegration time and hardness. From this study, the best candidate disintegrant was selected for use in further investigations.

\section{Assessment of disintegrating efficiency in tablet formulation}

The tablet formulations contained $20 \mathrm{mg}$ of propranolol hydrochloride, 2.5 or $10 \%$ of the selected polymer, $0.5 \%$ of magnesium stearate, $1 \%$ of fumed silica, and sufficient amounts of MCC to attain $100 \mathrm{mg}$ final weight. The blends for the tablet formulations were prepared by mixing the drug, selected polymer and MCC for $15 \mathrm{~min}$. Thereafter, fumed silica and magnesium stearate were added to the mixture and blended for a further $10 \mathrm{~min}$. The mixed powder was accurately weighed and compressed (1 ton force) using the press machine described earlier. The resultant tablets were assessed for hardness, friability, drug content, disintegration time and drug release. In addition, for comparison, drug tablets with sodium starch glycolate (SSG), but without disintegrant were prepared and evaluated.

\section{Tablet evaluation}

\section{Hardness}

The hardness of ten tablets randomly taken from each batch was measured in a hardness tester (THB 225TD, Erweka, Germany) and the mean hardness was recorded.

\section{Friability}

Twenty tablets were weighed and put in a friabilator (TA120, Erweka, Germany) operated at 100 revolutions for 4 min [4]. After brushing off dust particles, the tablets were weighed again and the friability (\%) was calculated in terms of percent weight loss.

\section{Drug content}

The drug content was determined in triplicate by dissolving each tested tablet in alcoholic solution. The mixture was properly diluted with phosphate buffer, $\mathrm{pH}$ 6.8, filtered and analyzed for propranolol hydrochloride content at the wavelength of $290 \mathrm{~nm}$ [13] using UV/Vis spectrophotometer (PG Instrument, United Kingdom). The drug content was expressed as \% of the label claim.

\section{Disintegration time}

Disintegration times for six tablets were evaluated using a USP disintegration apparatus (ZT323, Erweka, Germany) in deionized water at $37 \pm 0.5{ }^{\circ} \mathrm{C}$. The disintegration time was recorded at the moment when all tablet fragments passed through the assembly screen.

\section{Drug release}

Drug release study was carried out using a paddle dissolution apparatus (Prolabo, United Kingdom) rotating at $100 \mathrm{rpm}$ in $900 \mathrm{ml}$ of $0.1 \mathrm{~N}$ $\mathrm{HCl}(\mathrm{pH} 1.2)$ at $37 \pm 0.5 \stackrel{\circ}{\mathrm{C}}$. Samples of supernatant $(5 \mathrm{ml})$ were withdrawn at predetermined times and replaced with equivalent volume of fresh dissolution medium. The amount of drug released was determined spectrophotometrically at $290 \mathrm{~nm}$ [13]. Six tablets from each batch were examined in each test.

\section{Cytotoxicity test}

The cytotoxicity of polymers against Caco- 2 cells was evaluated in vitro with 3-(4,5-dimethylthiazol2-yl)-2,5-diphenyl-tetrazolium bromide (MTT) assay $[14,15]$. The Caco-2 cells were seeded in Dulbecco's modified Eagle's medium (DMEM) in a humidified atmosphere containing $95 \%$ relative humidity and $5 \% \mathrm{CO}_{2}$ at $37{ }^{\circ} \mathrm{C}$. At confluence, the cell was treated with the selected polymer and SSG at concentrations up to $10 \mathrm{mg} / \mathrm{ml}$ for 24 h. After treatment, the incubation medium was replaced with $200 \mathrm{ml}$ of MTT solution $(0.5 \mathrm{mg} / \mathrm{ml}$ in DMEM) and then incubated in a $\mathrm{CO}_{2}$ atmosphere for $1 \mathrm{~h}$. The supernatant was removed and the resultant formazan crystals were dissolved in dimethylsulfoxide (DMSO) (the number of viable cells is usually proportional to the amount of purple formazan crystals formed). Cell viability (\%) was computed based on the absorbance of the purple formazan solution at 
$550 \mathrm{~nm}$ in a microplate reader (AOPUS01, Packard BioScience, USA). The viability of nontreated cells $(100 \%)$ was set as control.

\section{Statistical analysis}

The data are presented as mean \pm standard deviation (SD). Statistical analysis of data was carried out with SPSS using one-way analysis of variance (ANOVA). Values of $p<0.05$ were considered significantly different.

\section{RESULTS}

The polymerization of MAA and $0.25-16 \%$ EGD formed stable crosslinked poly(MAA-co-EGD) in $\mathrm{H}$ form (Figure 2). The amount of cross-linker (EGD), i.e. the degree of crosslinking, had a profound effect on the texture of the resultant polymers. The polymer crosslinked at $0.25 \%$ cross-linker appeared as a hard plastic-like mass (Figure 2a), and was difficult to grind. However, with increase in the amount of cross-linker from 2 to $16 \%$, the resultant polymers were softer (Figure 2b-d), which facilitated comminution. Polymers in $\mathrm{Na}$ salt form were prepared by placing the ground polymers in $\mathrm{H}$ form in aqueous $\mathrm{NaOH}$. In this alkaline solution, $\mathrm{H}^{+}$of the polymers in acid form was displaced by $\mathrm{Na}^{+}$ so that the polymers were converted to their $\mathrm{Na}$ salts.

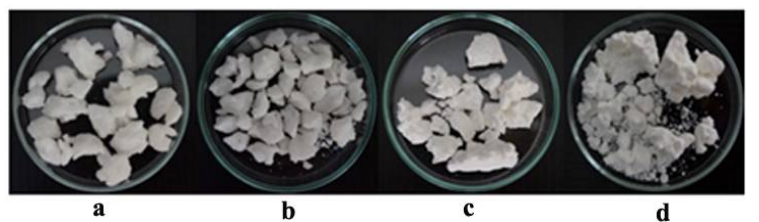

Figure 2: Appearance of poly(MAA-co-EGD) in $\mathrm{H}$ form at (a) 0.25 , (b) 2, (c) 8 and (d) $16 \%$ of EGD

Figure 3 presents the FTIR spectra of the synthesized polymers together with those of MAA, polymethacrylic acid (poly(MAA)) and EGD, for comparison. In the MAA spectrum (Figure $3 \mathrm{a}$ ), the $\mathrm{O}-\mathrm{H}$ and $\mathrm{C}=\mathrm{O}$ stretching of carboxyl group $(\mathrm{COOH})$ appeared as a broad peak at $3000 \mathrm{~cm}^{-1}$ and an intense peak at 1697 $\mathrm{cm}^{-1}$, respectively. The presence of the carboxyl group was supported by the $\mathrm{C}-\mathrm{O}$ stretching peaks at 1298 and $1204 \mathrm{~cm}^{-1}$. The $\mathrm{C}=\mathrm{C}$ stretching peak of MAA was observed at 1636 $\mathrm{cm}^{-1}$. The EGD spectrum showed a peak at 1718 $\mathrm{cm}^{-1}$ assigned to the $\mathrm{C}=\mathrm{O}$ stretching of the ester group, a peak at $1630 \mathrm{~cm}^{-1}$ assigned to the $\mathrm{C}=\mathrm{C}$ stretching, and peaks at 1299 and $1173 \mathrm{~cm}^{-1}$ assigned to the $\mathrm{C}-\mathrm{O}$ stretching of the ester group (Figure $3 b$ ). Poly(MAA) provided a different FTIR spectrum from its starting monomer (MAA), as shown in Figure 3c. The peak due to the $\mathrm{O}-\mathrm{H}$ stretching of the carboxyl group was broader and shifted to $3455 \mathrm{~cm}^{-1}$. In addition, the $\mathrm{C}=\mathrm{O}$ stretching peak was shifted to $1755 \mathrm{~cm}^{-1}$, while the $\mathrm{C}=\mathrm{C}$ stretching peak disappeared.

The FTIR spectra of differently crosslinked polymers in $\mathrm{H}$ form are shown in Figures $3 \mathrm{~d}-3 \mathrm{~g}$. The FTIR spectrum of the $0.25 \%$ crosslinked polymer (Figure 3d) was a superimposition between that of poly(MAA) and EGD, rather than MAA. As the amount of cross-linker (Figure $3 e-g$ ) was increased from 0.25 to $16 \%$, the intensity of the $\mathrm{O}-\mathrm{H}$ stretching peak was decreased, while the $\mathrm{C}=\mathrm{O}$ stretching peak disappeared because of the prevailing peak at $1718 \mathrm{~cm}^{-1}$ of the $\mathrm{C}=\mathrm{O}$ stretching from EGD (Figure 3b). The peaks at 1271 and $1173 \mathrm{~cm}^{-1}$ were related to the superimposed C-O stretching of the carboxyl and ester groups, which were also more evident from the increased amounts of cross-linker.

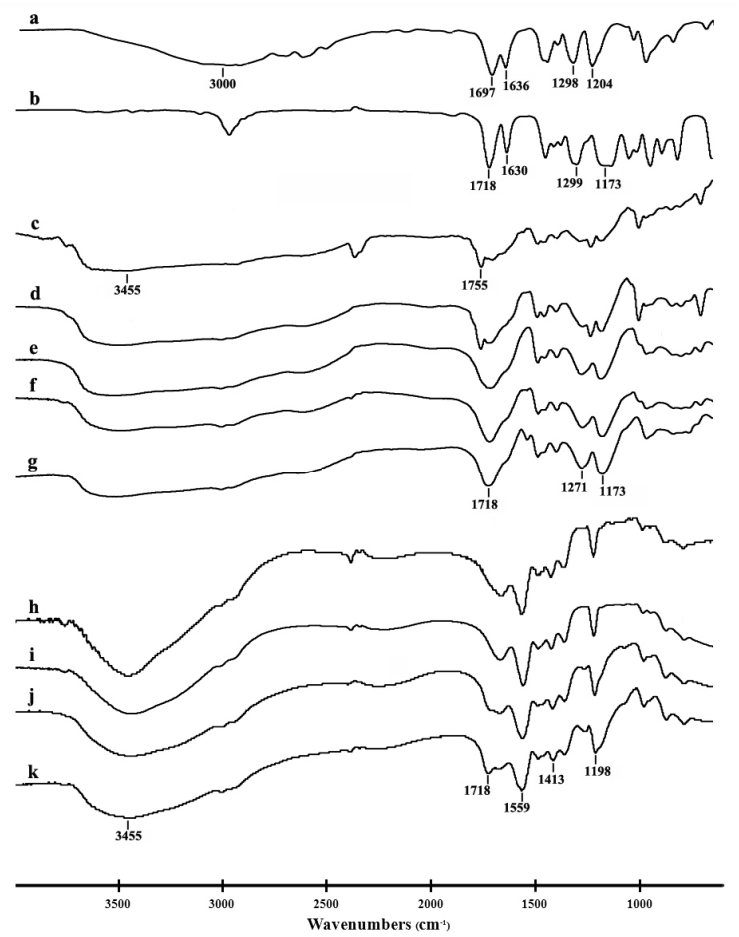

Figure 3: FTIR spectra of (a) MAA, (b) EGD, (c) poly(MAA) and poly(MAA-co-EGD) in $\mathrm{H}$ form at (d) 0.25 , (e) 2, (f) 8, (g) $16 \%$ EGD; and in $\mathrm{Na}$ form at (h) 0.25, (i) 2, (j) 8 and (k) $16 \%$ EGD

Figure $3(h-k)$ shows that the FTIR spectra of polymers in $\mathrm{Na}$ form clearly differed from those of the polymers in $\mathrm{H}$ form. After conversion to the salt forms, the peaks of $\mathrm{O}-\mathrm{H}$ and $\mathrm{C}=\mathrm{O}$ stretching from the carboxyl group significantly diminished and new peaks relating to the asymmetric and symmetric stretching of carboxylate anion ( $\left.\mathrm{COO}^{-}\right)$ occurred at 1559 and $1413 \mathrm{~cm}^{-1}$, respectively [16]. In addition, the $\mathrm{C}-\mathrm{O}$ stretching peaks originally found at 1271 and $1173 \mathrm{~cm}^{-1}$ changed to a single peak at $1198 \mathrm{~cm}^{-1}$, which was presumably due to the superimposed $\mathrm{C}-\mathrm{O}$ 
stretching of the carboxylate and ester groups. In Figure $3 \mathrm{k}$, the peak at $1718 \mathrm{~cm}^{-1}$ was assigned to the $\mathrm{C}=\mathrm{O}$ stretching of the ester group: it became gradually evident with increase in the amount of cross-linker.

The swelling capacities of the synthesized polymers are shown in Figure 4. The polymers in $\mathrm{Na}$ form swelled significantly more than those in $\mathrm{H}$ form $(p<0.05)$. The swelling capacity of polymers in $\mathrm{H}$ and $\mathrm{Na}$ forms decreased with increase in the amount of cross-linker $(p<0.05)$.

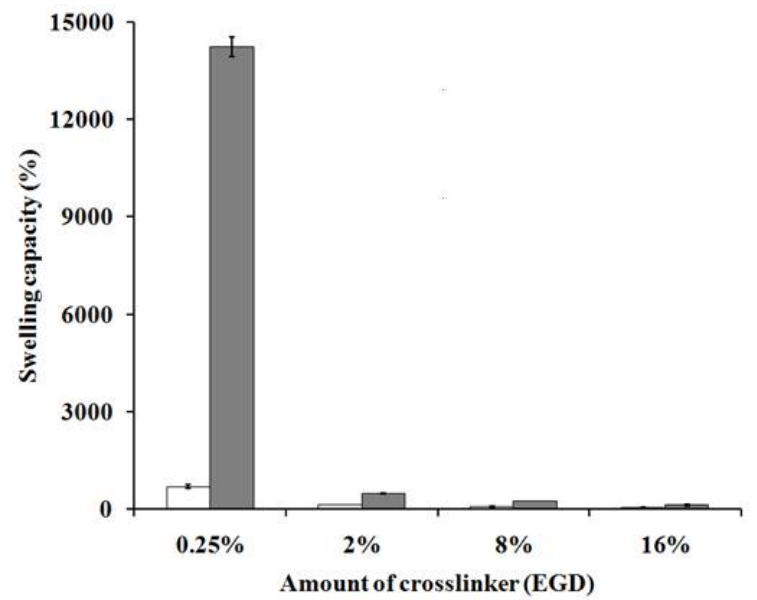

Figure 4: Swelling capacity of poly(MAA-co-EGD) in $\mathrm{H}$ form (clear bar) and $\mathrm{N}$ form (dark bar)

The disintegrating properties of polymers in $\mathrm{H}$ and $\mathrm{Na}$ forms were evaluated in placebo MCC tablets. The compression filler MCC was selected due to its excellent compactibility which results in hard tablets [1]. Thus the ability to break up a tablet made of MCC would suggest that the polymers would also be efficient disintegrants for tablets made from other compression fillers. As shown in Figure 5, MCC tablets containing the polymers provided high hardness and could disintegrate at different times. The disintegrating property of polymers was significantly influenced by the salt form and amount of cross-linker $(p<0.05)$.

These findings demonstrated that the polymers in $\mathrm{H}$ form were less effective as disintegrants

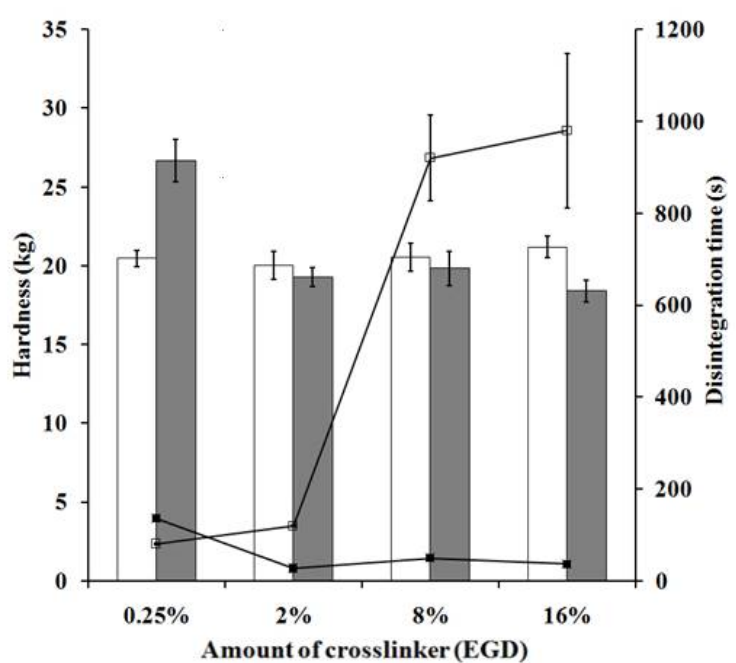

Figure 5: Hardness (bar graph) and disintegration time (line graph) of MCC tablets containing poly(MAAco-EGD) in $\mathrm{H}$ form (clear bar/symbol) and $\mathrm{N}$ form (dark bar/symbol)

than those in $\mathrm{Na}$ form. The disintegrating efficiencies of the polymers in $\mathrm{Na}$ form were comparable, regardless of the amount of crosslinker. As mentioned in the earlier section, the comminution of a highly crosslinked polymer is more successful and more conveniently than that of a lowly crosslinked one. Therefore, the polymer in $\mathrm{Na}$ form at $16 \%$ cross-linker was selected as the most suitable sample for further investigations.

The selected polymer was employed at 2.5 and $10 \%$ to formulate propranolol hydrochloride tablets using MCC as the tablet filler. Tablet formulations with SSG and without disintegrant were also prepared and compared. The properties and dissolution profiles of the formulated drug tablets are summarized in Table 1 and depicted in Figure 6, respectively.

The in vitro cytotoxicities of the selected polymer and SSG against Caco-2 cells were determined using MTT assay. The results from the test are shown in Figure 7.

Table 1: Properties of formulated propranolol hydrochloride tablets

\begin{tabular}{lcccc}
\hline Disintegrant & $\begin{array}{c}\text { Drug content } \\
(\% \text { label claim) }\end{array}$ & $\begin{array}{c}\text { Hardness } \\
(\mathbf{k g})\end{array}$ & $\begin{array}{c}\text { Disintegration } \\
\text { time (s) }\end{array}$ & $\begin{array}{c}\text { Friability } \\
(\%)\end{array}$ \\
\hline None & $99.8 \pm 1.2$ & $16.9 \pm 0.4$ & $5304.3 \pm 90.6$ & 0.199 \\
SSG 2.5\% & $95.1 \pm 1.1$ & $16.3 \pm 0.4$ & $740.3 \pm 8.0$ & 0.250 \\
Polymer 2.5\% & $96.6 \pm 2.1$ & $16.3 \pm 0.4$ & $474.7 \pm 3.6$ & 0.151 \\
SSG 10\% & $101.5 \pm 0.7$ & $15.6 \pm 0.3$ & $91.0 \pm 1.6$ & 0.329 \\
Polymer 10\% & $99.2 \pm 3.2$ & $11.6 \pm 0.5$ & $18.3 \pm 0.5$ & 0.020 \\
\hline
\end{tabular}

Poly(MAA-Co-EGD) in Na form at $16 \%$ cross-linker 


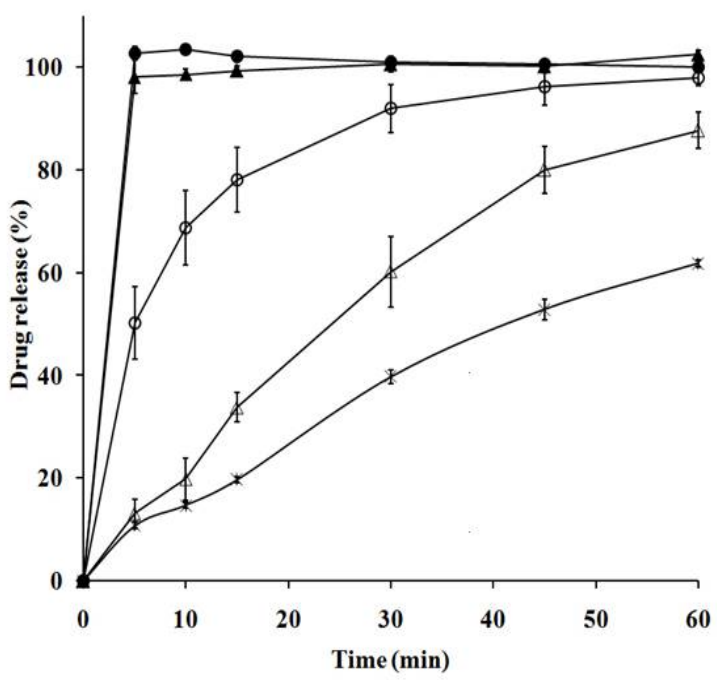

Figure 6: Drug release from propranolol hydrochloride tablets containing SSG at $2.5(\Delta)$ and $10 \%(\mathbf{\Delta})$; and from poly(MAA-co-EGD) in $\mathrm{Na}$ form at 2.5 (O), $10 \%$ $(\bullet)$ and without disintegrant $(\cdot)$

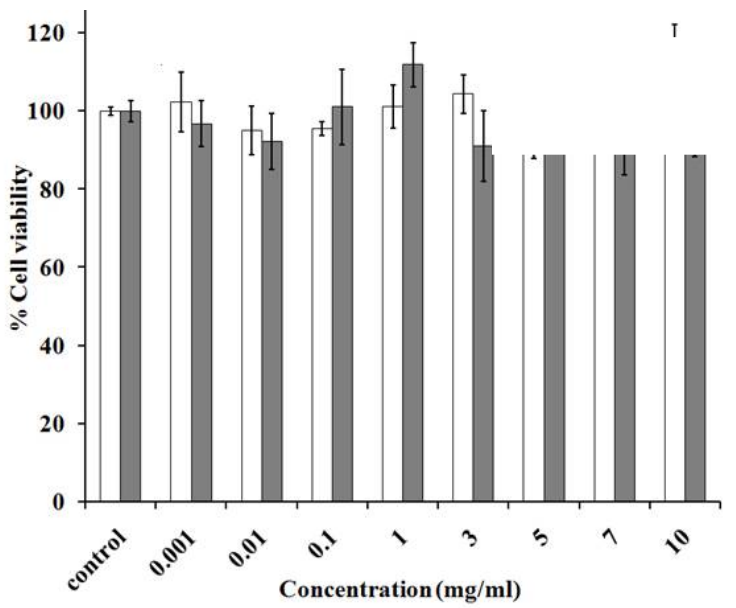

Figure 7: Viabilities of Caco-2 cells incubated with SSG (clear bar) and poly(MAA-co-EGD) (dark bar) in $\mathrm{Na}$ form for $24 \mathrm{~h}$

\section{DISCUSSION}

The results from spectral analyses indicated successful preparation of poly(MAA-co-EGD) in $\mathrm{H}$ and $\mathrm{Na}$ forms. The polymers behaved like hydrogels which were able to adsorb water and swell because of the presence of ionizable carboxyl or carboxylate groups. In the aqueous environment, these groups ionized, generating ionic $\left(\mathrm{H}^{+}, \mathrm{Na}^{+}\right.$and $\left.-\mathrm{COO}\right)$ solutions, and hence osmotic pressure inside the polymer network that acted as semi-permeable membrane. The resultant osmotic pressure brought about the adsorption of water and hence expansion of the polymer network (swelling). When the osmotic pressure became balanced, maximum swelling capacity was attained $[9,10]$. The polymers in $\mathrm{Na}$ form provided greater osmotic pressure and hence swelling capacity than those in $\mathrm{H}$ form because the carboxylate group ionizes better [17]. It has been shown that crosslinking hinders the expansion of the polymer chains [9]. Thus, in this study, the swelling capacity of the polymers decreased with increase in the amount of crosslinker.

The disintegrating efficiencies of polymers in $\mathrm{Na}$ form were higher than those in $\mathrm{H}$ form, corresponding to their higher swelling capacities, except for polymers crosslinked at $0.25 \%$ EGD. The higher hardness of the resultant tablet might be responsible for the lower disintegrating efficiency of the polymer in Na form at $0.25 \%$ of cross-linker in spite of having a higher swelling capacity. The effect of amounts of cross-linker on the disintegration efficiency was different between polymers in $\mathrm{H}$ and $\mathrm{Na}$ forms. The disintegrating efficiency of polymers in $\mathrm{H}$ form decreased with increasing the amount of crosslinker, leading to decreased swelling capacity. This dependency implies that the swelling action accounted for the disintegrating efficiency of the polymers in $\mathrm{H}$ form.

On the other hand, the disintegrating efficiency of polymers in $\mathrm{Na}$ forms was not influenced by the amount of cross-linker or swelling capacity. This might indicate that the disintegrating property of polymers in $\mathrm{Na}$ form did not solely result from the swelling action. A particle repulsion theory has been proposed by Guyot-Hermann $[1,18]$. In this proposal, it was postulated that electrical repulsive forces between particles cause the disintegrating action of non-swelling disintegrants. Perhaps, this mechanism also accounted for the disintegrating property of the polymers in $\mathrm{Na}$ form, which had a propensity for ionization, and hence electrostatic repulsion between particles.

The drug content of formulated propranolol hydrochloride tablets ranged from 95.1 to 101.5 $\%$ of the label claim. The drug tablets had comparable hardness, except for one containing $10 \%$ of the polymer which provided a relatively lower hardness. Nonetheless, it was considered hard enough for handling, as indicated by the fact that its low friability was comparable to those of other polymer. Drug tablets without disintegrant took one hour and a half to disintegrate, whereas tablets with the polymer took less than $10 \mathrm{~min}$. This indicated that the polymer acted effectively as a disintegrant for the tablet formulations. Similar to SSG, the disintegrating efficiency of the polymer was concentration-dependent, which is in agreement with results obtained in previous studies [2,6]. 
Drug release from tablets at $2.5 \%$ polymer was faster than drug release from tablets with SSG and without disintegrant, corresponding to the shorter time required for tablet disintegration. At this concentration, only the drug tablet containing the polymer met the USP dissolution specification for propranolol hydrochloride tablet, which requires that the amount of drug released from each tablet should not be less than $80 \%$ in $30 \mathrm{~min}$ [19]. Increasing the concentration from 2.5 to $10 \%$ resulted in the enhancement of drug release from the propranolol hydrochloride tablets containing the polymer and SSG because of the faster disintegration of tablets. Drug tablets with $10 \%$ of the polymer and SSG satisfied the USP dissolution specification for propranolol hydrochloride tablet by providing complete drug release within $5 \mathrm{~min}$. In contrast, the drug tablet without disintegrant had only $61.8 \%$ of drug release at the end of release testing $(60 \mathrm{~min})$.

There was no significant decrease in the viability of Caco-2 cells after exposure to the polymer. A similar result was obtained with SGG. Moreover, the viability of the Caco-2 cells incubated with the polymer was not significantly different from that obtained from SSG exposure. These results indicate that the polymeric disintegrant was as safe as SSG.

\section{CONCLUSION}

Poly(MAA-co-EGD) has been successfully developed as an efficient tablet disintegrant. The results show that its disintegrating efficiency is influenced by the amount of EGD, and its salt forms. Poly(MAA-co-EGD) possesses disintegration and dissolution attributes that are superior to those of sodium starch glycolate. Thus, this polymeric material has potentials for use as a new super-disintegrant for tablet formulations. However, appropriate investigations have to be carried out first to ascertain its safety profile.

\section{DECLARATIONS}

\section{Acknowledgement}

The authors thank Silpakorn University Research and Development Institute for funding this research and Faculty of Pharmacy, Silpakorn University, Nakhon Pathom, Thailand for facility supports.

\section{Conflict of Interest}

No conflict of interest associated with this work.

\section{Contribution of Authors}

The authors declare that this work was done by the authors named in this article and all liabilities pertaining to claims relating to the content of this article will be borne by them.

\section{REFERENCES}

1. Rudnic EM, Kottke MK. Tablet dosage forms. In: Banker, Gilbert S.; Rhodes, Christopher T., editors. Modern pharmaceutics third edition, revised and expanded. New York: Marcel Dekker, 1996; pp 333-394.

2. Odeku OA, Akinwande BL. Effect of the mode of incorporation on the disintegrant properties of acid modified water and white yam starches. Saudi Pharm J 2012; 20: 171-175.

3. Adebayo SA, Myrie EB, Itiola OA. Comparative disintegrant activities of breadfruit starch and official corn starch. Powder Technol 2008; 181: 98-103.

4. Boonwatcharapan $Y$, Srisuk $P$, Palladino $P$, Sutthiparinyanont $S$, Chitopas $P$. Preparation and evaluation of alcohol-alkaline-treated rice starch as a tablet disintegrant. Trop J Pharm Res 2016; 15: 221229.

5. Ahuja M, Kumar A, Yadav $P$, Singh K. Mimosa pudica seed mucilage: isolation; characterization and evaluation as tablet disintegrant and binder. Int $J$ Biol Macromol 2013; 57: 105-110.

6. Chang RK, Shinwari $M$, Leonzio $M$, Wu LS, Pang J, Hussain MA. Evaluation of the disintegrant properties for an experimental, crosslinked polyalkylammonium polymer. Int J Pharm 1998; 173: 87-92.

7. El-Barghouthi M, Eftaiha A, Rashid I, Al-Remawi M, Badwan A. A novel superdisintegrating agent made from physically modified chitosan with silicon dioxide. Drug Dev Ind Pharm 2008; 34: 373-383.

8. Sadeghi M, Hemmati S, Hamishehkar H. Synthesis of a novel superdisintegrant by starch derivatization with polysuccinimide and its application for the development of Ondansetron fast dissolving tablet. Drug Dev Ind Pharm 2015; 14: 1-7.

9. Garcia DM, Escobar JL, Bada N, Casquero J, Hernaez E, Katime I. Synthesis and characterization of poly(methacrylic acid) hydrogels for metoclopramide delivery. Eur Polym J 2004; 40: 1637-1643.

10. Garcia DM, Escobar JL, Noa Y, Bada N, Hernaez E, Katime I. Timolol maleate release from $\mathrm{pH}$-sensible poly(2-hydroxyethyl methacrylate-co-methacrylic acid) hydrogels. Eur Polym J 2004; 40: 1683-1690.

11. Beamish JA, Zhu J, Kottke MK, Marchant RE. The effects of monoacrylated poly(ethylene glycol) on the properties of poly(ethylene glycol) diacrylate hydrogels used for tissue engineering. J Biomed Mater Res A 2010; 92: 441-50.

12. Rashid I, Al-Remawi M, Leharne SA, Chowdhry BZ, Badwan A. A novel multifunctional pharmaceutical excipient: Modification of the permeability of starch by 
processing with magnesium silicate. Int J Pharm 2011; 411: 18-26.

13. Gil EC, Colarte Al, Bataille B, Pedraz JL, Rodríguez F, Heinämäki J. Development and optimization of a novel sustained-release dextran tablet formulation for propranolol hydrochloride. Int J Pharm 2006; 317: 3239 .

14. Mosmann T. Rapid colorimetric assay for cellular growth and survival: Application to proliferation and cytotoxicity assays. J Immunol Method 1983; 65: 55-63.

15. Woraphatphadung $T$, Sajomsang $W$, Gonil $P$, Treetong $A$, Akkaramongkolporn $P$, Ngawhirunpat $T$, Opanasopit $P$. pH-Responsive polymeric micelles based on amphiphilic chitosan derivatives: Effect of hydrophobic cores on oral meloxicam delivery. Int J Pharm 2016; 497: 150-160.
16. Lambert, Joseph B.; Shurvell, Herbert F.; Verbit, Lawrence; Cooks, Robert G.; Stout, George H. Organic structural analysis. New York: MacMillan; 1976; $p 239$.

17. Martin, Alfred; Swarbrick, James; Cammarata, Arthur. Physical chemical principles in the pharmaceutical sciences. 3rd edn. Philadelphia: Lea \& Febiger, 1983; $p$ 190.

18. Guyot-Hermann AM, Ringard J. Disintegration mechanisms of tablets containing starches. Hypothesis about the particle-particle repulsive force. Drug Dev Ind Pharm 1981; 7: 155-177.

19. The United State Pharmacopoeia 39. Rockville MD: United State Pharmacopoeial Convention; 2016. 